\title{
Correction to: Interventions to Reduce Adverse Drug Event-Related Outcomes in Older Adults: A Systematic Review and Meta-analysis
}

\author{
Sarah Tecklenborg ${ }^{1} \cdot$ Catherine Byrne $^{1,2} \cdot$ Caitriona Cahir $^{1} \cdot$ Lamorna Brown $^{1} \cdot$ Kathleen Bennett $^{1}(\mathbb{D}$
}

Published online: 27 January 2020

(c) Springer Nature Switzerland AG 2020

\section{Correction to: Drugs \& Aging}

https://doi.org/10.1007/s40266-019-00738-w

Unfortunately, the co-author name was incorrectly published as "Lamona" instead of "Lamorna" in the original article. The correct version of the author name is updated here.

The original article has been corrected.

The original article can be found online at https://doi.org/10.1007/ s40266-019-00738-w.

Kathleen Bennett

kathleenebennett@rcsi.ie

1 Division of Population Health Sciences, Royal College of Surgeons in Ireland, St Stephen's Green, Dublin 2, Ireland

2 Health Products Regulatory Authority, Earlsfort Terrace, Dublin 2, Ireland 